\title{
3. ENTREVISTAS
}

\section{"EL FREPASO ES UNA FUERZA POLITICA QUE NO TIENE MIEDO A DEBATIR" ENTREVISTA A JOSE OCTAVIO BORDON}

\author{
por Ana Inés López-Accotto y Grabiela Delamata
}

El ex-senador justicialista, José Octavio Bordón, encabeza - junto a Carlos "Chacho" Alvarez- una nueva formación política, el FREPASO, que ha irrumpido con fuerza en el mapa electoral argentino en las elecciones generales del mes de mayo. Pocos meses después, como consecuencia de negociaciones públicas realizadas sin consultar a sus compañeros frentistas, Bordón se granjeó una fuerte oposición interna. Esta situación le llevó a dimitir de todos sus cargos, institucionales y partidistas. No obstante, ALH ha considerado que sus reflexione sobre Argentina presentan aspectos interesantes, por lo que se ha decidido su publicación, más allá de los avatares de la política cotidiana.

\section{ALH: ¿Qué es el Frente del País Solidario (FREPASO)?}

Bordón: Más allá de los aspectos formales, es la confluencia de cuatro fuerzas políticas que son el Frente Grande, el Partido País, la Democracia Cristiana y la Unidad Socialista. También es un espacio de confluencia donde hay gente que se siente partícipe del espacio en su conjunto, no de cada una de las fuerzas. No solamente hay demócratas cristianos y socialistas sino también han llegado muchos dirigentes provinientes del justicialismo, otros de la Unión Cívica Radical, incluso algunos de otras fuerzas políticas provinciales y mucha gente independiente. Esto desde un punto de vista de origen de gestión. Crece y se fortalece, yo diría a partir del Pacto de Olivos y de la insuficiencia que para mucha gente tienen los dos partidos políticos tradicionales para dar respuestas nuevas a los problemas que hoy se están planteando.

Desde un punto de vista filosófico, el mínimo común denominador es el de una filosofía humanista que se expresa con una visión de una democracia pluralista y participativa en la que la economía debe funcionar en el marco de un mercado pero que tiene unas reglas de juego para impedir que este mercado se vuelva monopólico u oligopólico con perjuicio de la democracia económica, esto es, del desarrollo de los pequeños y medianos productores y empresarios en general y de los sectores del consumo y del trabajo.

Y por último, creemos que todo proceso de transformación y de crecimiento tiene que partir de una idea equitativa para poder garantizar una justicia social como objetivo. Yo lo sintetizo así: "dime cómo ahorras, cómo inviertes, cómo acumulas y te diré cómo creces y cómo vas a distribuir". Esto está claramente en contraposición, al menos en los tiempos modernos, con la idea de creer que se puede acumular y crecer de una manera injusta y que luego esto va a derramar lógicamente justicia social entre la gente.

Yo diría que estos son, de una manera muy sencilla, nuestras principaes propuestas que en el plano nacional se expresan en la defensa permanente de lo que es la cultura, el trabajo y la producción de los argentinos. En el plano internacional luchamos por la libertad, por la justicia social y por la defensa del medio ambiente, a través de medios diplomáticos y pací ficos. Creemos que hay dos tendencias que deben ser armonizadas en el mundo: una tendencia hacia la universalización que es lógico que puede hasta ser positivo para lograr mayores niveles de justicia, de paz y de equidad. Pero que también la gente exige, y con razón, que se respete su cultura, sus pequeños espacios, sus grandes temas cotidianos. Plantear una globalización destruyendo lo que son valores cotidianos, o los valores locales, las culturas es peligroso. Estas serían las ideas centrales y fundamentales desde un punto de vista filosófico-político.

ALH: ¿Cómo se conjugan las diferentes tradiciones e imaginarios polí ticos que confluyen en el FREPASO /tradición radical, peronista, socialista, demócrata-cristiana), teniendo en cuenta que desde 1945 hasta hoy la línea divisoria fundamental ha sido peronismolantiperonismo?

Bordón: Primero, nosotros no estamos divididos por los temas del pasado (tenemos nuestra interpretación histórica de lo que ha sucedido), sino que estamos fundamentalmente unidos por los temas que desafían al presente y, sobre todo, de cara al tercer milenio.

Segundo, creemos que además hay un hecho histórico y cultural que ha permitido esta transversalidad y ha logrado coincidencias entre gente de distintos partidos, inclusive con algunos que hoy no están en el FREPASO y que están en otras fuerzas políticas. Y que esto tiene que ver con que nuestra generación y algunas otras generaciones más jóvenes, la de los hombres que estamos en promedio alrededor de los cincuenta años, con cinco por abajo o por arriba -yo estoy justamente en el medio-, hemos vivido dos procesos históricos muy peculiares, donde hemos sido protagonistas: el 66-73, la dictadura de esos años y el Proceso militar 76-83. En el primero no solamente se trataba de proscribir al peronismo y a Perón sino que planteó proscribir a la política, a los jóvenes y al pensamiento. Y esto nos encontró luchando codo con codo por la libertad, por la justicia social por la democracia, el derecho a pensar, a personas que estábamos en el justicialismo, en la democracia cristiana, en el socialismo, en el radicalismo. Y ahí tuvimos estrategias de trabajo en común y diálogos y seminarios juntos y manifestaciones contra la dictadura y luchas y persecuciones. Y el 
sentimiento de que recuperar la democracia era una tarea en conjunto, no de uno u otro.

Además, una parte importante de nuestra generación miraba absorta y casi sin encontrar espacio, aunque algunos tenian protagonismo cuando en tres años de democracia la violencia reemplazó a las palabras en nombre de posturas ideológicas de uno u otro signo y comenzó a crecer lo que fueron las Tres A, lo que luego sería el terrorismo de Estado.

Y después vino otra etapa. Ahí buscamos dialogar; además muchos de nosotros nos sentíamos plenamente comprendidos y consustanciados con esta decisión de Perón y de Balbín de plantear que pertenecíamos a una misma cultura aunque estuviéramos en perspectivas y en debates desde distintos lugares; pero perteneciamos a una misma cultura argentina y dentro de eso habia una lucha pluralista, un consenso pluralista de construir el pais.

Y después vino la historia del 76 al 83. Ya no se trataba ahí solamente de proscribir a la política sino de proscribir a la Argentina. Y bueno, los que pudimos sobrevivir físicamente y con voluntad politica y además hemos sobrevivido del 83 para acá (en un proceso que nos hizo perder tantos dirigentes como la violencia, que ha sido la corrupción y el escepticismo, el pragmatismo vacío de valores), creo que hoy este humanismo (en mi caso y en el de algunos otros que viene del humanismo trascendente, para otros viene del humanismo socialista, con tradiciones distintas, como pueden ser los estilos radicales y el peronista...A veces nosotros comentamos "no es que desaparecen absolutamente porque yo no puedo borrar treinta años de mi vida cuando los he vivido con pasión, con entusiasmo y feliz de haber hecho esa opción, como otros han hecho otras"), yo creo que la hemos defendido positivamente y con honestidad.

Pero estas circunstancias de diferencias tienen dos características: primero, en términos globales, son menores las distintas maneras de ser humanistas y democráticos frente a la deshumanización del capitalismo salvaje, del pragmatismo vacío de valores. Segundo, porque cuando observamos a los partidos políticos tradicionales, las diferencias que hay de posturas entre ellos son mucho más amplias que las que tenemos entre nosotros, aunque tengan a favor "la camiseta" común, el signo o sus músicas.

Esto sirve, no son temas menores tampoco: desde el punto de vista de esos partidos, las diferencias que puede haber entre Alsogaray - como parte ya estable de la alianza gobernante del menemismo- o Cavallo y muchos de los legisladores o gobernadores o intendentes o militantes del justicialismo son mucho más amplias que las que hay entre hombres de distintos partidos que conforman el Frente del País Solidario. Lo mismo en la Unión Cívica Radical, entre los sectores que coinciden bastante más con las ideas de Cavallo y aquellos que son absolutamente diferentes de éstos. La diferencia es mucho mayor que la que hoy se vive en el FREPASO.

Lo que es cierto es que nosotros tenemos que construir sobre este mínimo común denominador filosófico, moral, doctrinario y programático que ya tenemos y vamos a seguir desarrollando y perfeccionando. Creemos que es más que suficiente. Viene ahora un máximo común denominador de prácticas, de nuevos estilos, de sistemas coincidentes de elección de candidatos, de mecanismos de representación, incluso hasta de ciertos signos (desde los colores, el nombre o lo que se llamó FREPASO), que nos vaya unificando, más allá de que seamos una confederación de partidos. Es una tarea ardua, interesante pero absolutamente posible de hacer.

Creo que este es el clima en el cual estamos; estos son los temas que hemos conseguido; estos son los desafíos que nos quedan por delante. Y yo diría que esto se va a lograr básicamente, para mí, si superamos algo que hasta hoy hemos hecho mucho y bien: las pequeñeces que todo ser humano tiene y que en toda actividad dirigencial, sea empresarial o social y, obviamente, en la política, siempre aparecen. En la medida en que sigamos con la misma actitud, yo diría ética, de poner el proyecto de conjunto por encima de situaciones particulares, creo que esto va a seguir creciendo y en muy buena medida.

Sobre todo no tenemos miedo de debatir. Somos una fuerza política que debate. A mí lo que me preocupó del justicialismo es que el último debate doctrinario lo dimos en la ciudad de Mendoza - más de mil quinientos dirigentes-, entre los cuales estábamos Alvarez y yo, (fuimos los que convocamos) y el actual presidente, [Menem], en 1989: "La comunidad organizada hacia el siglo XXI". Fue el último debate que se da en el justicialismo. Nunca más se debatió: se asumió el gobierno, se cambió totalmente un programa, pasaron cosas importantísimas y no se debatió nada de esto. Hubo, sí, un debate subterráneo, un debate en las catacumbas, diría yo.

Nosotros tenemos que empezar a debatir fuertemente muchos temas; además, por la velocidad de los cambios, uno debe estar en una actitud de debate permanente; pero, al mismo tiempo, en una actitud crítica, constructiva, porque si uno debate y debate y no llega a sintesis y propuestas, no es una fuerza política que de respuesta y alternativa a la gente. Debatir con velocidad, con profundidad y al mismo tiempo encontrar sistemáticamente sintesis es fundamental. Y no nos llame la atención que desde las fuerzas politicas tradicionales, especialmente desde el menemismo, quieran llamar a esto división, anarquía y caos; y a la falta de debate interno y a la lucha subterránea y callada la quieran llamar unidad. La unidad existe en el marco de los objetivos en común, producto del debate interno. La sintesis final pluralista, donde nadie impone siempre sus posturas sino donde encontramos un punto de sintesis necesario.

Yo creo que estos cuatro años son una gran tarea cultural. Mucha gente creyó en nosotros, no solamente todos los que nos votaron sino algunos que finalmente no nos votaron. Pero muchos de los que creyeron en nosotros por la ética, porque querian más equidad, nos decían: "ipor qué no nombró el ministro de economía?" Y aquí hay un debate cultural: economía no es lo que Menem y Cavallo y ciertos popes dicen que es economía. La economía es otra cosa, que va desde la defensa del medio ambiente hasta la justicia independiente y hasta un mejor ambiente institucional y social, que pasa por la calidad y la equidad de la educación y de la salud. Además de poder tener ideas claras y concretas sobre cómo hacer una reforma financiera, cómo manejar con más eficiencia que lo que han hecho Menem y Cavallo el sistema de liquidez y el ingreso de capital internacional (otros países lo manejaron mejor que como se hizo en Argentina y por eso tuvieron menos dificultades). Yo sé que estos problemas hay que manejarlos, pero es una lucha cultural entender que economía no es solamente eso. Economía son muchas más cosas y nosotros queremos una economia con la gente adentro.

ALH: ¿es la gente la que está cambiando la manera de entender y de plantearse los problemas? ¿Es así como debe entenderse al electorado del FREPASO?

Bordón: Hoy el sujeto histórico fundamental de este cambio que nosotros proponemos son las personas. No es una clase social determinada, no. Son las personas. Tienen una inquietud frente a problemas; esta inquietud no está organizada.

¿Qué somos nosotros? Gente que les decimos que compartimos su inquietud y que comenzamos a lanzar estilos e ideas que entendemos pueden resolver esta inquietud. 0 esta insatisfacción. 0 esta angustia por no saber qué nos pasa. Y esta es la tarea finalmente de la acción intelectual y práctica de la política. Es comprender y ser parte común, como personas, como comunidad, de las inquietudes, las angustias y los problemas que tenemos e ir encontrando las respuestas y los caminos.

Sabemos que existe esto y no aceptamos que no nos dejen pensar. No aceptamos esta nueva inquisición, que en lugar de quemarnos desde afuera para que no pensemos, es como que se nos ha instalado y nos quema desde adentro y nos impide animarnos a pensar porque tenemos miedo de no estar a la moda de quienes supuestamente manejan los códigos. Pero yo, frente a quienes supuestamente manejan los códigos, digo que el mundo me muestra que la mitad de la gente no llega a tener los mínimos alimentos y conocimientos que hoy definen la dignidad de un ser humano y que no tenemos seguridad de que mis nietos van a poder ver los peces, los árboles y los pájaros y tener los ríos en los cuales yo crecí. Entonces frente a esto, no aceptamos no pensar. Y la inquietud no la queremos matar sino que la queremos asumir para que nos ayude a encontrar respuestas.

ALH: ¿Quiénes son los que han respondido con su voto a las propuestas del FREPASO?

Bordón: En una rápida visión son sectores medios -la clase media en Argentina es muy amplia, va desde un trabajador hasta pequeños y medianos empresarios, pasando por profesionales, técnicos y docentes-. Son urbanos: ésto puede tener tambiên algunas connotaciones de la novedad de nuestras propuestas, ya que a las zonas más alejadas se tarda más en llegar: 0 que, quizás, aunque han sido las más afectadas, todavía no están totalmente ganadas por el escepticismo. Y en tercer lugar -aunque lo tenemos que analizar-, digamos que nos ha ido mejor en los sectores más informados, ya sea en los sectores altos, medios o bajos que en los menos informados. No hablo de mayor o menor educación sino de información e interés por los temas de la política. Y esto demuestra que también nos falta todavía más tiempo de trabajo para llegar hasta el último rincón. Llegar hasta el último rincón nos va a permitir también enriquecer y perfeccionar nuestras propias propuestas.

Nosotros aspiramos a servir al conjunto de los argentinos. Pero sí dijimos que queríamos reconstituir una Argentina de clase media, de esta amplia clase media que a mediados del setenta estábamos a punto de lograr: una sociedad dinámica, abierta, con igualdad de oportunidades, que fue construida con una lenta, progresiva arquitectura social, que duró casi un siglo en la Argentina y que desde el proceso militar comenzó a desarticularse, en este proceso de dualización, de fragmentación, de concentración económica, que no se mejoró en los primeros años de la democracia y que lamentablemente se ha profundizado de una manera sin precedentes durante la vigencia del actual modelo del menemismo.

Entendiendo además que esta sociedad de clase media es la que nos permite, por su dinamismo, instrumentar las politicas modernas y dignificadoras que nos permitan luchar contra la pobreza. Porque las politicas sociales de las sociedades que económicamente tienden a la dualización y/o a la fragmentación, son políticas sociales que más que resolver el tema de la pobreza tienden a contener a los pobres en la pobreza sin que exploten. Y ésto, en la práctica política de algunos lugares, como en la Argentina, se convierte en el 
clientelismo político y sustento de caudillos locales que asociados sostienen poderes nacionales. Esto va acompañado de una práctica de escepticismo, de hacerle creer a la gente que no hay alternativas. Entonces, si no hay alternativa, nos quedamos con este clientelismo que hoy tenemos.

En ese sentido creemos que ha respondido la gente que pensamos que puede tener una inicial y mayor capacidad de dinamización; pero obviamente nuestra aspiración es que nos voten los que tienen trabajo pero están insatisfechos 0 cultural o económica o institucionalmente, también los que no tienen trabajo y los que están más alejados, los que menos tienen. Por ellos, con ellos y para ellos queremos trabajar.

Una sociedad con tanta exclusión (un 30 por ciento de los argentinos está bajo la línea de pobreza y cada vez más fuera del ámbito formal y normal del conocimiento y de los bienes materiales), no solamente es un drama para ellos sino que también va siendo más rígida y va poniendo cada vez más en peligro la situación de los sectores medios. Y, al mismo tiempo, comprendiendo que la decadencia y la crisis de los sectores medios no hace más que profundizar y agudizar el problema de la pobreza. Así que se trata de tener una práctica política permanente de estar cerca de los temas pero también una propuesta política donde rompamos este aislamiento, esta fragmentación que nos lleva a una cultura egoísta, del sálvese quien pueda, en la cual cada vez se salvan menos y nos va peor.

ALH: ¿En qué consiste el programa económico alternativo del FREPASO, en el contexto de lo que Ud. denominó "capitalismo salvaje"?

Bordón: Primero, en no aceptar la tecnocracia economicista. Ya algunos premios nobel de economía dijeron "por favor, déjennos pensar". Y nos están reduciendo a una teoría; y a una parcela de la economía la han convertido en ley de la economía. Así que lo primero es rebelarse contra eso, como tema más general. Porque en la medida en que veamos la multiplicidad de sectores que nos han llevado a esta dificultad, también vamos a encontrar la multiplicidad de espacios y de propuestas que podemos poner en marcha. Porque si uno quiere resolver toda esta compleja situación desde una monosolución, finalmente nunca la puede poner en marcha. Uno debe tener un objetivo claro de adónde quiere ir pero si tiene decenas de caminos o de acciones que desarrollar, por las cuales transitar, seguramente va a encontrar espacio para hacerlo.

Segundo, ya en una parcela muy precisa, concreta y muy práctica de Argentina en la actualidad, habíamos planteado que en el marco del congelamiento en la estabilidad y en el programa menem-cavallista, las crisis que iban a aparecer después del 14 de mayo - ya aparecieron-iban a dejar a este modelo con dos opciones: devaluación (que iba a ser peor el remedio que la enfermedad), o recesión con desempleo y pérdida de niveles salariales, que claramente es el camino que han asumido y van a asumir y al cual pondrán algunas presiones fiscales mayores (porque un exceso de recesión puede llevar a crear problemas fiscales serios por las dificultades de recaudar).

Frente a esto que habíamos previsto que era así, intentaron hacer creer que nosotros decíamos que no había otra alternativa: dijeron que queríamos bajar sueldos, cosas por el estilo. Estábamos hablando del modelo de ellos, no del nuestro. ¿Qué planteamos? Planteamos claramente un modelo que atacara los bolsones de corrupción, de ineficiencia y los privile gios. Y esto ya es un cambio de programa: que no fuera concentrador sino desconcentrador. Y entonces decíamos que en esa lucha, en cuatro años nos sentíamos capaces de liberar entre 6 mil y 8 mil millones de pesos 10 de dólares) de los ochenta y tantos mil millones de pesos del gasto público argentino, incluyendo la administración central, las provinciales y las municipales. Y que esto progresivamente lo íbamos a volcar sobre ciertos sectores prioritarios en términos de la inversión, que iban a ser el sector del conocimiento (cultura, ciencia y técnica, educación). Lo que planteábamos era ir a un 6 por ciento del PBI, como idea global, para dar una idea del esfuerzo que había que hacer.

Nos parece central porque el conocimiento es el nuevo nombre de la soberanía. Y es el nuevo nombre de la competitividad: si en serio queremos ser competitivos tenemos que pensar en ésto. Como alguien dijo alguna vez en la India, somos demasiado pobres como para no invertir en educación y en ciencia y técnica. Y esta es una verdadera decisión transformadora, que no es sólo decir que la educación es una prioridad sino animarnos a dar esta lucha. Y diciendo claramente que debíamos invertir más pero convocando a la transformación; porque sin más recursos no podemos convocar al cambio en conocimiento. Pero poner más plata para lo mismo tampoco nos permitía el cambio.

Segundo, en el tema previsional -que paso más rápidamente en este tema, no porque sea poco importante sino porque quizás sea menos importante para el centro de la pregunta.

Y el tercero, políticas activas en lo financiero, en lo tecnológico, en la conformación de consorcios de exportación, de la construcción, de infraestructura y en el mejoramiento de las redes de comercialización de los pequeños y medianos empresarios, detrás de un objetivo nuestro que era ser un país crecientemente exportador, fuerte en bienes agroindustriales e in dustriales, del mayor valor agregado posible versus esta primarización del modelo callavista.
Y, como queremos estabilidad y equilibrio, planteamos los costos fiscales que tendría, por ejemplo, que la Argentina incorporara doscientas empresas por año al ISO 9000/9004 como elementos de calidad internacional que permitiría ingresar en ciertos mercados (Brasil tiene 600 y sigue creciendo, frente Argentina que tiene 10, para dar una idea de cómo dificulta esto la integración y la competitividad). Y sabíamos cuál era el costo fiscal de ésto, entre 20 y 30 millones de dólares -a este grado de detalle habíamos llegado ya-. Deciamos que en todos estos casos, las políticas activas que no transgredan el marco del GATT sino que están en el marco del GATT, o la entrega de financiamiento a términos internacionales mientras haciamos la reforma financiera, tienen que estar explicitadas en el presupuesto para no tener desequilibrios fiscales. Y las financiamos progresivamente con esta lucha contra la ineficiencia, los bolsones de corrupción y los privilegios. Con una visión distinta e integradora.

Estos son elementos que más hemos trabajado. Jugamos realmente a una estabilidad más firme que el gobierno actual. Porque nuestro modelo crecientemente exportador de agroindustria con un alto valor agregado tiene tres virtudes: primero que genera nuevos puestos de trabajo, que es nuestro objetivo final; segundo que este modelo, a diferencia del modelo primarista, primario exportador, en la medida en que fortalece el mercado externo fortalece el mercado interno. Y, en tercer lugar, porque logra divisas genuinas para seguir fortaleciendo la propia economía y la propia estabilidad.

Sé que hay que hablar de muchas más cosas pero esta es una visión sencilla y precisa del plan de objetivos, en esta visión distinta y superadora de la economía. Y empezamos con un punto primero que era la austeridad y la honestidad porque la austeridad recupera el espíritu de ahorro e inversión, que es muy importante para una sociedad; y la austeridad y la honestidad son elementos muy importantes para esta lucha contra la ineficiencia en el gasto público $y$, con su consecuente independencia de cualquier tipo de poder corporativo o sectorial, permiten enfrentar en mejores condiciones las limitantes internas y externas a este proceso democratizador en lo económico y en lo social. Cuando uno es empleado de los que limitan, ya no solamente tiene la presión externa sino que tiene la presión interna. Cuando uno no es empleado, tiene la posibilidad de dialogar, discutir y encontrar la ecuación posible detrás de los objetivos que uno se plantea.

ALH: ¿Eso implica, de alguna manera, atribuir un papel diferente al estado del que le ha otorgado el actual proyecto neoliberal?

Bordón: Sin lugar a dudas. Yo creo que el modelo que uno podría definir como el de la sociedad de bienestar 0 , más concretamente, una versión de este modelo hizo crisis a mediados de la década de los setenta. La incapacidad para ponernos de acuerdo de cómo lo bueno se iba convirtiendo en malo y el rol importante del estado se iba convirtiendo en burocracia y corrupción, en ineficiencia, en lugar de ser puentes se convertían en obstáculos, nos hizo reaccionar muy tarde. Y después, cuando reaccionamos, compramos una ideología que reemplazó el estado de bienestar por el estado de malestar (como dicen algunos buenos intelectuales latinoamericanos y algunos militantes del FREPASO en sus trabajos para UNICEF).

Yo creo que lo que había que hacer era pasar del estado de bienestar a una sociedad de calidad de vida que exige posiblemente un estado más pequeño que el anterior. No necesariamente mucho más pequeño que el que hoy tiene la Argentina. Pero mucho más activo y eficiente y dinámico. Aquí realmente se instaló, en algunos con inocencia en otros con absoluta premeditación, la idea de que el estado es en sí malo, ineficiente y corrupto, que es tan perversa como aquella idea de que lo privado es en sí malo.

Nosotros creemos que puede haber procesos desestatizadores, descentralizadores, desburocratizadores, guiados hacia un proceso de mayor participación y democratización económica y social y de mayor capacidad de control y de acción de las personas en la sociedad, contrarios a un estatismo extremo. Pero creemos que el modelo actual directamente significó la ruptura de las cadenas de producción, de solidaridad y tremendos procesos de concentración que nos llevaron a una situación muy difícil. En consecuencia, no se trata de reconstituir una sociedad estatista pero sí un estado ágil y moderno que permita una sociedad de calidad de vida, mucho más equitativa.

ALH: ¿Cuál es la posición del FREPASO frente a las políticas de privatización? ¿Se considera que hay sectores que son estratégicos y que, por lo tanto, no deben privatizarse?

Bordón: Diría que ante cada privatización, ante cada acción que hace el estado hay que preguntarse si es mejor o peor que esté en manos del estado o en manos privadas. Y decidir en consecuencia. Yo nunca privaticé hasta tener la convicción de que eso me ayudaba a hacer más democrática y equitativa a la sociedad y no dudé en privatizar cuando estaba seguro de que podía mejorar. Así que más que definirlo así, yo lo definiría desde cada situación, con esta filosofía.

Obviamente, en la situación argentina actual, yo hoy no privatizaría a las empresas binacionales de energía, casos Salto Grande y Yaciretá. Después de un año de trabajo, en el que veníamos planteando como reformular y modernizar todo el sistema de la Comisión Nacional de Energía Ató- 
mica y hemos estado más de un año de cara a la sociedad, contando con los funcionarios e investigadores y todos los especialistas en el sector, obviamente nos oponemos a las privatizaciones. Creemos que tienen una idea de caja, una vez más. Y creemos que como ya se les agotaron las joyas de la abuela porque financiaron con stock gastos corrientes, en lugar de haber usado esos stocks para modernizar la actividad productiva y para ampliar el potencial productivo, entonces ahora quieren vender a la abuela, que vendrían a ser estas tres empresas. Como en toda la última etapa: a ver si cubren este y el año que viene ya veremos.

Lo mismo que se hizo con Mercosur; ahora empieza a haber complicaciones. Esto no lo digo ahora, lo tengo escrito: las negociaciones de Mercosur las pensaron exclusivamente buscando que Brasil nos reactivara a corto plazo, nos equilibrara la balanza del año 95. Y se dejó de lado el debate sobre el perfil de complementación industrial y de valor agregado y la necesidad de buscar confluencias para ser más competitivos juntos en el mundo. Ahora comienzan a plantearse algunos problemas, que están expresando que se dejaron de lado sectores muy importantes: inclusive había sectores agroindustriales importantísimos que fueron deteriorados en el Acuerdo, (aunque ya los distintos sectores empresarios de ambos países, aún los competitivos, habían acordado una política de conjunto), fueron en desmedro del sector argentino dejados de lado por los equipos negociadores del gobierno nacional, en una visión en la que simplemente interesaban los equilibrios macro, sin una visión de empleo, de tecnología, de conocimiento, de industria, de competitividad internacional, que Brasil no deja de lado. Y si nosotros no lo dejamos de lado no va a haber conflicto con Brasil sino que vamos a tener un modelo más fuerte entre los dos. Cuando digo Brasil, digo Uruguay, digo Paraguay, digo Chile (no porque Chile esté en el Mercosur sino por las relaciones de cooperación del Mercosur con Chile o de Argentina con Chile).

ALH: ¿Hay algún modelo de administración pública existente que le resulta especialmente interesante como referencia para Argentina?

Bordón: Desde que empecé a estudiar medicina siempre supe que la anatomía descriptiva era insuficiente si además no estudiaba bien la anatomía comparada. Siempre supe que la salud no empezaba por la anatomía sino por el centro de salud, por la gente, por el hospital. Así que se trata de saber qué queremos hacer con la sociedad para saber qué queremos hacer con el estado. Si no, al revés, desde el punto de vista del privatismo como del estatismo, vamos a tener una concepción errónea y simplificada de lo que es el estado.

Creo que es importante la sociología, la política y la administración comparada $y$ en mis viajes y cuando enviamos gente a estudiar afuera o cuando recibimos becarios en nuestra Fundación, primero buscamos la riqueza que supone siempre la comparación. Pero de ahí a la copia sería muy peligroso. Obviamente hay experiencias en países cercanos, (de Chile, por ejemplo en el tema de modelos de exportación) que son interesantes; hay experiencias del sistema federal norteamericano, de organización de justicia, que son interesantes; hay temas de la administración y de la formación en Francia que son ricos e interesantes; hay temas del funcionamiento del federalismo alemán que tiene características diferentes a lo que nosotros hemos estado estudiando. Pero no me quedaría con un modelo.

ALH: En América Latina la forma de hacer política siempre ha estado identificada con el personalismo, el populismo o el seudopopulismo. iSignifica esto un lastre para los que quieren cambiar la forma de hacer política?

Bordón: Esto tiene que ver con las historias y peculiaridades, siempre ciertos tipos de liderazgo juegan: sería muy difícil comprender la Francia moderna sin el liderazgo de De Gaulle, lo cual no quiere decir que se suprimieran las instituciones; sería imposible de entender los Estados Unidos durante cuarenta años sin el liderazgo de Roosevelt, del quien a veces decimos que salvó al capitalismo a pesar de los capitalistas, más allá de ellos. Pero creo entender la pregunta. Yo creo que hemos llegado al fin del tema de los liderazgos caudillistas; que hoy deben ser liderazgos democráticos e institucionales, desde la ejemplaridad que tenemos que dar desde el poder, de una austeridad y una sobriedad, respeto por las instituciones, por las reglas de juego, por la previsibilidad, pasando por los sistemas de elección y selección dirigencial.

Para la realidad de nuestro país proponemos como método de selec ción las elecciones internas abiertas - que significa que pueden participar todas las personas-, para que no se hagan camarillas o burocracias entre los afiliados al partido. Y lo que llamamos la posibilidad de listas de preferencia, donde en igualdad de oportunidades, si hay que elegir cinco cargos puede haber cinco mujeres, cinco hombres y cinco o tres jóvenes y que uno pueda elegir un nombre de cualquier lista. Y la apertura a que la gente pueda elegir para que se armonice la capacidad política con la capacidad de ser un buen docente, un buen vecino. Todos ellos nos parecen temas que son realmente importantes.

El tema de los partidos y la creación de instituciones, institutos y fundaciones que se ocupen seriamente de la formación de dirigentes políticos modernos, es tambiên muy importante; legislaciones mucho más claras y precisas en término a la transparencia, a la democratización y a la equidad en el sistema de financiamiento de los partidos políticos. Yo presenté una ley de "manos limpias y libres" hace más de un año, en Argentina, y aun que no la aprobaron, me la autoapliqué durante la última campaña. Significa no solamente mejorar la calidad y la transparencia de la dirigencia sino también significa $-\mathrm{y}$ lo puse ahí por escrito y en la repetición del proyecto lo he vuelto a decir- luchar contra un peligro que puede haber en el futuro en la política en el mundo: que frente a los mejores sistemas de control de impuestos que se hacen y que cierra el camino a las empresas locales para financiar en negro - una característica negativa y peligrosa que yo no acepto-, comiencen a financiarse sectores políticos con dinero de la corrupción internacional de la droga, del armamento y del juego. Entonces se necesita mucha transparencia respecto a quién aporta y en el control de lo que se gasta.

Y por último, entre esta serie de "recetas" -voy a cosas prácticasme parece que hay que encontrar métodos nuevos. El viejo método del lo cal partidario, donde reuniones fijadas a las ocho y media empezaban a las once y terminaban a las tres de la mañana, es una hermosa manera para excluir a la gente, especialmente a las mujeres que en el día de hoy no solamente tienen una profesión y un trabajo sino que todavía, lamentablemente, parecen ser las exclusivas responsables de las tareas familiares. Lo que eran espacios de participación han devenido espacios de marginación En este sentido hemos buscado métodos nuevos: desde los encuentros domiciliarios, métodos de cassette, de películas, interactivos, la utilización del teléfono y del sistema de internet para conectarnos dentro y fuera del país. Y otros temas que estamos discutiendo y elaborando para encontrar métodos nuevos que aumenten y mejoren la participación.

ALH: Teniendo en cuenta los resultados de las últimas elecciones ¿puede decirse que ha cambiado el mapa politico en Argentina?

Bordón: Sí, indudablemente. Primero porque Menem sorprendió a propios y extraños, en 1989, entre lo que proponía (que a nosotros nos parecía excesivo y poco realista) hasta lo que hizo, que nos pareció tan realista que dejó a mucha gente afuera. Ahora está claro: es un programa de centro-derecha y quienes lo han votado creen en eso. Aunque no tenga proyecto ideológico. Yo creo que se ha afirmado como una propuesta de centro-derecha, para expresarlo en términos europeos.

Segundo, se produce el mayor deterioro histórico de la Unión Cívica Radical, que es una tendencia desde el ochenta y siete a la fecha. Y, por primera vez en los últimos cincuenta años, apareció una fuerza política nueva como segunda fuerza. El FREPASO, en algún sentido, no tiene antecedentes en Argentina: en muy poco tiempo estuvo muy cerca de ganar; $y$ es la segunda fuerza sin contar casi con recursos económicos - costó cuarenta centavos cada voto que conseguimos frente a diez dólares de los que consiguió el oficialismo, para dar una medida de la vitalidad de la gente-.

Creo que se ha modificado el mapa. Mapa que también hay que leer en otro sentido: que estamos en promedio dos a uno en la fórmula presidencial en relación a los dirigentes o candidaturas locales, lo que más que hablar de la supervirtud de la fórmula o del candidato a presidente, está hablando también de la debilidad de lo nuevo a nivel local. Ahí está el trabajo muy intenso que resta por hacer.

Cómo va a ser el futuro mapa. Yo creo que no sería correcto que yo confundiera mi profesión de sociólogo con mi responsabilidad como dirigente político y especialmente mi rol en la sociedad argentina y en el FREPASO. Partiendo de ésto, no es posible decir hoy que hay un cien por cien de posibilidades de que nosotros ocupemos el primer lugar o que hay un cien por ciento de posibilidades de que el radicalismo vaya a desaparecer aunque sea el último partido Radical que queda con cierto protagonismo en América Latina.

Yo diría que quedan dos escenarios posibles. Un escenario de dos fuerzas políticas grandes con otras menores, esto es, el menemismo por un lado y el FREPASO por el otro, expresando dos alternativas dentro de un único sistema político institucional; y por otra parte, la posibilidad, si el radicalismo reacciona, de que haya tres fuerzas políticas importantes y fuerzas políticas menores: el radicalismo, el FREPASO y el menemismo. Este es el panorama que vemos. Muchas cosas de lo que vaya a pasar en el futuro dependerá de lo que nosotros hagamos tam biến. De que lo hagamos bien o no. Yo tengo la confianza de que así como en diciembre dije que si hacíamos una interna abierta nos íbamos a fortalecer y pasó así; y que podíamos pelear de igual a igual y estuvimos ahî, al borde, tengo la misma convicción de que somos una fuerza política nueva que tiene grandes posibilidades. Más allá de un 95 que va a ser difícil, sobre todo en siete de los nueve distritos electorales -las mejores posibilidades son en Santa Fé, la Capital Federal-, creo que las elecciones que renueven el 50 por ciento de las bancas legislativas en 1997 van a ser el gran momento para terminar de afianzar electoralmente esta fuerza y ponerla en la base de ser el próximo gobierno nacional a partir del 10 de diciembre del 99 .

Madrid, $16 / \mathrm{VI} / 95$ 